\title{
In vitro proliferation and osteogenic differentiation of mesenchymal stem cells on nanoporous alumina
}

This article was published in the following Dove Press journal:

International Journal of Nanomedicine

26 July 2013

Number of times this article has been viewed

\author{
Yuanhui Song' \\ Yang Ju' \\ Guanbin Song² \\ Yasuyuki Morita' \\ 'Department of Mechanical Science \\ and Engineering, Nagoya University, \\ Nagoya, Japan; ${ }^{2}$ Key Laboratory \\ of Biorheological Science and \\ Technology, Ministry of Education, \\ College of Bioengineering, \\ Chongqing University, Chongqing, \\ People's Republic of China
}

\begin{abstract}
Cell adhesion, migration, and proliferation are significantly affected by the surface topography of the substrates on which the cells are cultured. Alumina is one of the most popular implant materials used in orthopedics, but few data are available concerning the cellular responses of mesenchymal stem cells (MSCs) grown on nanoporous structures. MSCs were cultured on smooth alumina substrates and nanoporous alumina substrates to investigate the interaction between surface topographies of nanoporous alumina and cellular behavior. Nanoporous alumina substrates with pore sizes of $20 \mathrm{~nm}$ and $100 \mathrm{~nm}$ were used to evaluate the effect of pore size on MSCs as measured by proliferation, morphology, expression of integrin $\beta 1$, and osteogenic differentiation. An MTT assay was used to measure cell viability of MSCs on different substrates, and determined that cell viability decreased with increasing pore size. Scanning electron microscopy was used to investigate the effect of pore size on cell morphology. Extremely elongated cells and prominent cell membrane protrusions were observed in cells cultured on alumina with the larger pore size. The expression of integrin $\beta 1$ was enhanced in MSCs cultured on porous alumina, revealing that porous alumina substrates were more favorable for cell growth than smooth alumina substrates. Higher levels of osteoblastic differentiation markers such as alkaline phosphatase, osteocalcin, and mineralization were detected in cells cultured on alumina with $100 \mathrm{~nm}$ pores compared with cells cultured on alumina with either $20 \mathrm{~nm}$ pores or smooth alumina. This work demonstrates that cellular behavior is affected by variation in pore size, providing new insight into the potential application of this novel biocompatible material for the developing field of tissue engineering.

Keywords: nanoporous alumina, mesenchymal stem cells, proliferation, differentiation, tissue engineering
\end{abstract}

\section{Introduction}

Tissue engineering is an emerging interdisciplinary field that applies the principles of biology and engineering to the development of functional substitutes that restore, maintain, or improve the function of damaged tissue or organs. A major challenge of tissue engineering is to design functional materials that can promote productive and efficient cellular activity. With the advancement of material science, biologically inspired materials are being designed to promote biocompatibility and enhance cellmaterial interactions to improve the integration of medical implants. ${ }^{1}$

Cellular behaviors, such as changes in adhesion, morphology, migration, and orientation, as well as focal adhesions and cytoskeleton development and differentiation, are known to be highly affected by the surface topography and local microenvironment of the substrate. Features of an implant surface, such as composition, topography, and
Correspondence: Yang Ju

Department of Mechanical Science and Engineering, Nagoya University, Furo-cho, Chikusa-ku, Nagoya 464-8603, Japan

Tel 81527894672

Fax81527893109

Email ju@mech.nagoya-u.ac.jp 
roughness, play an important role in cell-material integration. ${ }^{2,3}$ Surface engineering with advanced technologies, including the incorporation of nanotopography, can be used to mimic the natural repair process of the human body, because these surface topographic features on the nanoscale may resemble the natural extracellular matrix in which cells reside and interact. ${ }^{4}$ It is therefore hypothesized that nanoscale topographic surface cues can be tailored to regulate cell function in much the same way as the extracellular matrix regulates cell function. Previous studies have shown that a topographically patterned surface and chemical surface features can provide controllable cell-material interaction that influences cellular responses ranging from morphology and alignment to adhesion, growth, and differentiation. ${ }^{5-7}$

Alumina has been used widely as an implanted inorganic scaffold material in tissue engineering because of its biocompatibility and mechanical properties. Porous alumina has received a great deal of attention from the field of bone regeneration, because bone cells can penetrate throughout the interconnected pores and grow on their biocompatible surfaces, which would be expected to promote fast bone ingrowth by providing a three-dimensional environment. ${ }^{8,9}$ Previous studies have demonstrated that it is possible to influence cellular attachment and mineralization of osteoblasts by varying the pore size of nanoporous alumina. ${ }^{10}$ Swan et al found that a nanoporous alumina substrate with $72 \mathrm{~nm}$ pores promoted osteoblast adhesion. ${ }^{11}$ The HepG 2 hepatoma cell line was observed to have grown homogeneously over the nanostructured alumina surface. ${ }^{12}$ The high porosity also allows diffusion of nutrients, oxygen, and waste products, which is advantageous for cell growth. These reports indicate that nanoporous alumina could be regarded as an ideal cell culture substrate for further tissue engineering application.

Another current challenge in the development of tissue engineering is the lack of a renewable cell source. Stem cells are promising cell sources in therapeutic and regenerative medicine. As immature or undifferentiated cell types, stem cells are able to differentiate into a variety of more specialized cell types, such as osteoblasts, chondroblasts, myoblasts, adipocytes, and tenocytes under certain types of stimulation. ${ }^{13-17}$ Further, stem cells can easily be harvested from donor sites and cultured into a wide range of tissues. Stem cells are therefore becoming an attractive cell source for the repair of damaged or defective tissues and organs in the human body.

Numerous studies have focused on the response of stem cells to nanostructured materials. However, few data are available concerning cellular responses of mesenchymal stem cells (MSCs) to nanoporous alumina. Understanding the influence of nanoporous alumina surface topography on the behavior of MSCs is of crucial importance in developing biomaterials for orthopedic surgery and tissue engineering.

The purpose of the present study was to investigate the in vitro behavior of MSCs cultured on nanoporous alumina substrates with different pore sizes, and the effect of nanosize on cell adhesion, proliferation, morphology, and osteogenic differentiation.

\section{Materials and methods Nanoporous alumina}

Commercially available nanoporous alumina membranes with pore diameters of $20 \mathrm{~nm}$ and $100 \mathrm{~nm}\left(\right.$ Anodisc $^{\circledR}$, Whatman International Ltd, Maidstone, UK) were used in this study. The membranes were ultrasonically cleaned twice in ethanol for 30 minutes each, and then dried at room temperature on a clean bench. They were stored in a vacuum oven until use. Smooth alumina was purchased from Alfa Aesar (Ward Hill, MA, USA) and used as a control. The alumina was washed with ethanol and distilled water before use. The surface topography of the membranes was examined with a scanning electron microscope (7000FK, JEOL Ltd, Tokyo, Japan).

\section{Surface characterization with atomic force microscopy}

Nanoporous alumina surface topography were characterized by atomic force microscopy (Veeco NanoMan VS-1N) in the tapping mode. The force applied to the cantilever was adjusted manually to approximately $50 \mathrm{pN}$. This force was just sufficient for the stylus of the cantilever to remain in contact with the surface during the scanning process. To optimize image quality, the scanning rate was kept between $0.5 \mathrm{~Hz}$ and $2 \mathrm{~Hz}$ and feedback gains were finely tuned during imaging.

\section{Culture of MSCs}

MSCs were purchased from the Health Science Research Resources Bank, Osaka, Japan. The cells were cultured in $25 \mathrm{~cm}^{2}$ flasks at $37^{\circ} \mathrm{C}$ in a humidified incubator containing $5 \% \mathrm{CO}_{2}$. The culture medium was Dulbecco's Modified Eagle's Medium (Gibco, Grand Island, NY, USA) supplemented with $10 \%$ fetal bovine serum, $100 \mathrm{U} / \mathrm{mL}$ of penicillin, and $100 \mu \mathrm{g} / \mathrm{mL}$ of streptomycin. Upon reaching confluence, cells were detached with $0.05 \%$ trypsin $/ 0.02 \%$ ethylenediamine tetra-acetic acid, collected by centrifugation, and resuspended in Dulbecco's Modified Eagle's Medium. The cells were counted using a hemocytometer, and approximately $2 \times 10^{5}$ cells were seeded onto the alumina membrane. The membranes were then incubated at $37^{\circ} \mathrm{C}$ for 
6 hours to allow the cells to attach to the material, after which the alumina membranes were transferred to a new cell culture plate. An osteoblast differentiation medium (Cell Application Inc, San Diego, CA, USA) was employed for osteogenic differentiation. All media were changed every 3 days.

\section{Cell viability}

An MTT (3-(4,5-Dimethylthiazol-2-yl)-2,5-diphenyltetrazolium bromide) assay was used to estimate the density of viable cells on the substrates. After the MSCs were cultured on the nanostructured alumina surface for 1,4 , and 7 days, the medium was changed and $200 \mu \mathrm{L}$ of MTT $5 \mathrm{mg} / \mathrm{mL}$ (Wako Pure Chemical Industries Ltd, Osaka, Japan) was added and incubated at $37^{\circ} \mathrm{C}$ for another 4 hours. The medium containing MTT was removed and $1.5 \mathrm{~mL}$ of dimethyl sulfoxide was added to each well to dissolve the formazan crystals. The optical density of the solution was measured at a wavelength of $490 \mathrm{~nm}$ with a microplate reader (680, Bio-Rad, Hercules, CA, USA).

\section{Immunofluorescence staining}

After 2 days of culture, the MSCs that adhered to substrates were fixed with $4 \%$ paraformaldehyde at room temperature for 20 minutes. Samples were then washed three times with phosphate-buffered saline and permeabilized with $0.25 \%$ Triton X-100 at room temperature for 30 minutes. The treated samples were then incubated with $1 \%$ bovine serum albumin/phosphate-buffered saline at $37^{\circ} \mathrm{C}$ for one hour. Subsequently, a goat monoclonal antibody against integrin $\beta 1$ (1:200 dilution, Santa Cruz Biotechnology, Santa Cruz, CA, USA) was added at $4^{\circ} \mathrm{C}$, and the samples were allowed to stand overnight. Mouse-antigoat rhodamineconjugated secondary antibody (1:100 dilution, Santa Cruz Biotechnology) was then added at room temperature and allowed to stand for 10 minutes. The samples were rinsed three times with phosphate-buffered saline, stained with $0.5 \mu \mathrm{M}$ Alexa Fluor 488-conjugated phalloidin, and allowed to stand at room temperature for 2 hours. The nuclei of the MSCs were stained with $10 \mu \mathrm{g} / \mathrm{mL}$ DAPI (4',6-diamidino2-phenylindole), counterstained with mounting medium, and allowed to stand at room temperature for 5 minutes. The stained samples were then observed by confocal laser scanning microscopy (Nikon, Tokyo, Japan).

\section{Observation and analysis of cell morphology}

To observe cell morphology on the nanoporous alumina substrates, the cells were rinsed with phosphate-buffered saline after incubation for 4 days, and then fixed with $2.5 \%$ glutaraldehyde (Wako Pure Chemical Industries Ltd) in phosphate-buffered saline for one hour at room temperature. After thorough washing with phosphate-buffered saline, the cells were dehydrated in a graded series of ethanol $(70 \%, 80 \%, 90 \%, 95 \%$, and $99.5 \%)$ for 15 minutes each and air-dried at room temperature. The fixed samples were sputter-coated with gold (E-200S, Canon, Tokyo, Japan) and cell morphology was examined using scanning electron microscopy.

The length and width of the MSCs were measured using Image J software as measures of the differences in cell morphology observed in the scanning electron microscopy results. The ratio of obtained cell length to cell width was termed the cell elongation ratio. At least 30 cells in each group were measured.

\section{Alkaline phosphatase activity}

Quantitative detection of alkaline phosphatase activity was determined using an assay based on the hydrolysis of p-nitrophenylphosphate to p-nitrophenol to measure osteogenic differentiation of MSCs cultured on the substrate. MSCs were cultured on nanostructured alumina substrates for 1,2 , and 3 weeks. Next, $20 \mu \mathrm{L}$ of the cell lysate was added to $100 \mu \mathrm{L}$ of working reagent. The samples were then incubated at $37^{\circ} \mathrm{C}$ for 15 minutes. After incubation, the reaction was stopped with $80 \mu \mathrm{L}$ of sodium hydroxide. Absorption at a wavelength of $405 \mathrm{~nm}$ was measured using a 680 spectrophotometric microplate reader (Bio-Rad). Alkaline phosphatase activity was normalized by total intracellular protein production and expressed as micromoles per milligram protein per minute.

Total protein content was measured using a bicinchoninic acid protein assay. The cell-based scaffolds were assayed after culture for 1, 2, and 3 weeks. After the medium was removed from the cell culture, the MSCs were washed with phosphate-buffered saline, and $300 \mu \mathrm{L}$ of a detergent-based lysis buffer (M-PER Mammalian Protein Extraction Reagent, Pierce Chemical Co, Rockford, IL, USA) and a protease inhibitor (phenylmethylsulfonyl fluoride and ethylenediamine tetra-acetic acid, 1:100 dilution) were added to collect the total cellular protein. Total protein content in the cell lysates was measured using a bicinchoninic acid assay kit (Pierce Chemical Co). Next, $25 \mu \mathrm{L}$ of Triton lysate was added to $200 \mu \mathrm{L}$ of bicinchoninic acid working solution, and the mixture was incubated for 30 minutes at $37^{\circ} \mathrm{C}$. The protein concentration was determined from the absorbance at a wavelength 
of $570 \mathrm{~nm}$ by a 680 spectrophotometric microreader (Bio-Rad).

\section{Real-time PCR}

Total ribonucleic acid (RNA) of the cells on different substrates was extracted using an RNeasy Mini Kit (Qiagen, Valencia, CA, USA). Reverse transcripts were performed using a High Capacity RNA-to-cDNA kit (Applied Biosystems, Bedford, MA, USA) with approximately $1.5 \mu \mathrm{g}$ of total RNA in a final $20 \mu \mathrm{L}$ reaction volume. Real-time polymerase chain reaction (PCR) was performed using a Taqman Gene Expression Master Mix (Applied Biosystems) on a 7300 real-time PCR system (Applied Biosystems). Predesigned MGB probes of glyceraldehyde 3-phosphate dehydrogenase (GAPDH, Hs99999905_m1), integrin $\beta 1$ (Hs00559595_m1), and osteocalcin (Hs00609452_g1) (Applied Biosystems) were used to detect relative gene expression. The GAPDH expression level was used as an endogenous control. Expression levels were normalized to GAPDH and calculated using a standard curve method.

\section{Mineralization assay}

Alizarin red staining was used to detect mineralization. The staining was performed after incubation for 4 weeks, as described in a previous study. ${ }^{18}$ Cultured cells were fixed in 4\% paraformaldehyde and treated with $40 \mathrm{mM}$ Alizarin red S ( $\mathrm{pH} 4.1$, Sigma, St Louis, MO, USA) for 20 minutes at room temperature. The mixture was gently shaken. After aspiration of the unincorporated dye, the samples were washed four times with distilled water while they were shaken for 5 minutes. To quantify staining, 10\% $\mathrm{v} / \mathrm{v}$ acetic acid was added to each sample and incubated for 30 minutes while the sample was shaken. The surface layer on the substrate was collected with acetic acid $(10 \%, \mathrm{v} / \mathrm{v})$ and transferred to microcentrifuge tubes. The tubes were heated to $85^{\circ} \mathrm{C}$ for 10 minutes and then centrifuged at 20,000 g per minute for 15 minutes. The supernatant was transferred to a new microcentrifuge tube and neutralized with $10 \% \mathrm{v} / \mathrm{v}$ ammonium hydroxide. Absorbance of the supernatant was measured at a wavelength of $405 \mathrm{~nm}$ using a 680 spectrophotometric microplate reader (Bio-Rad).

\section{Statistical analysis}

Data are represented as the mean \pm the standard deviation. Statistical analysis to compare results between two groups was carried out using an unpaired Student's $t$-test. $P<0.05$ was considered to be statistically significant.

\section{Results}

\section{Surface characterization}

Figure 1A-C shows scanning electron microscopic images of the surface topography of smooth alumina and nanoporous alumina with $20 \mathrm{~nm}$ and $100 \mathrm{~nm}$ pores, respectively. The nanoporous alumina surfaces were flat, and the circular pores were homogeneously distributed on the surface. The depth of the pores was $60 \mu \mathrm{m}$, which is the same as the thickness of the membranes. Figure 1D shows a cross-sectional scanning electron microscopic image of nanoporous alumina with pores of $100 \mathrm{~nm}$. The surface contact area of porous alumina was obtained by calculations from the scanning electron microscopic images in Figure $1 \mathrm{~B}$ and $\mathrm{C}$ using ImageJ software (Figure 1E). Porous alumina with $20 \mathrm{~nm}$ pores showed a larger contact area than alumina with $100 \mathrm{~nm}$ pores. The surface topography and profile of the alumina substrates was characterized by atomic force microscopy. Three-dimensional surface topographies of the smooth alumina and nanoporous alumina are shown in Figure $2 \mathrm{~A}-\mathrm{C}$, respectively, and their corresponding surface profiles are shown in Figure 2D-F. The valleys observed in Figure 2B and $\mathrm{C}$ indicate pores on the membranes. The profiles shown in Figure 2E and F suggest that the pores were uniformly distributed on the alumina surfaces and that the pore diameter corresponded to the values measured by scanning electron microscopy.

\section{Cell viability}

An MTT assay was used to evaluate the viability of MSCs cultured on different substrates. The representative absorbance of the MSCs is shown in Figure 3. MSCs cultured on nanoporous alumina substrates with either $20 \mathrm{~nm}$ pores or $100 \mathrm{~nm}$ pores showed significantly higher cell viability $(P<0.05)$ than those cultured on smooth alumina after incubation for 4 days and 7 days. This result indicates that porous alumina is advantageous for cell growth. However, cell viability decreased with increasing pore size.

\section{Immunofluorescence staining and expression of integrin $\beta$ I}

Cytoskeletal actin, nuclei, and integrin $\beta 1$ were immunostained to investigate the adhesion and spreading of MSCs on different substrates (Figure 4A). MSCs cultured on nanoporous alumina showed clearly enhanced integrin $\beta 1$ expression compared with those on smooth alumina. The expression of integrin $\beta 1$ was also quantitatively analyzed using real-time PCR (Figure 4B). The expression of integrin $\beta 1$ in MSCs cultured on nanoporous alumina was relatively higher than that 

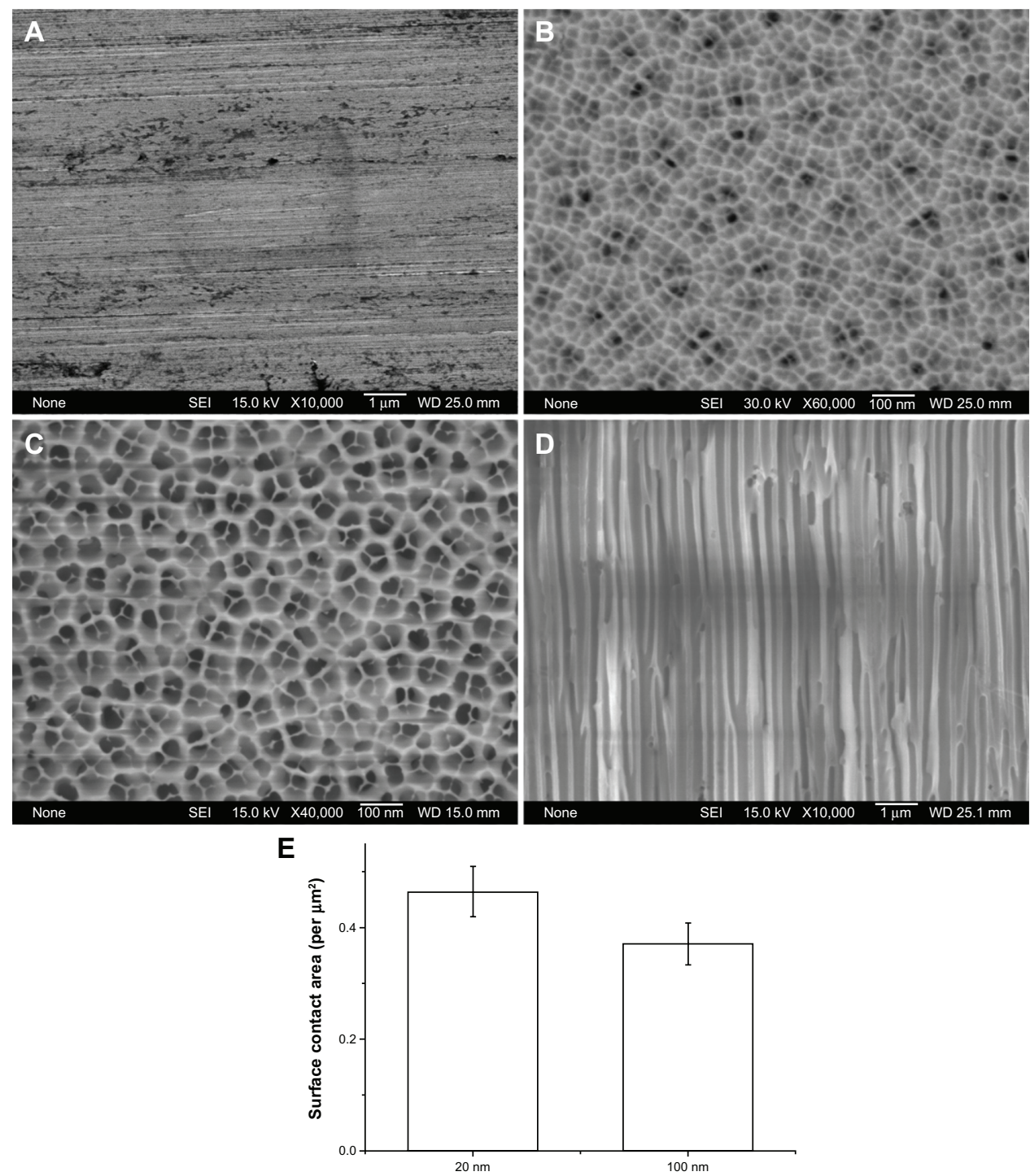

Figure I Scanning electron microscopic images of (A) a smooth alumina surface, (B and $\mathbf{C})$ nanoporous alumina surfaces with pore diameters of $20 \mathrm{~nm}$ and I00 $\mathrm{nm}$, respectively; (D) a cross-sectional scanning electron microscopic image of nanoporous alumina with $100 \mathrm{~nm}$ pores, and (E) surface contact area of alumina with different pore sizes.

in MSCs cultured on smooth alumina, but the difference was not significant $(P>0.05)$. The expression of integrin $\beta 1$ in cells cultured on nanoporous alumina with $20 \mathrm{~nm}$ pores was higher than in those cultured on alumina with $100 \mathrm{~nm}$ pores.

\section{Morphology of MSCs}

MSCs were cultured on different alumina substrates for 4 days and observed using scanning electron microscopy to observe the effect of surface topography on cell morphology (Figure 5). MSCs cultured on smooth alumina appeared to be rounder and more stationary than those cultured on alumina with $20 \mathrm{~nm}$ or $100 \mathrm{~nm}$ pores. They lacked noticeable filopodia extensions (Figure 5A and D). Cells cultured on alumina with $20 \mathrm{~nm}$ pores exhibited a higher level of cell spreading than the $100 \mathrm{~nm}$ group (Figure 5B and E). However, elongated cell morphology and prominent filopodia extensions were also observed in cells cultured on alumina with $100 \mathrm{~nm}$ pores (Figure 5C and $\mathrm{F}$ ).

Cell elongation was quantitatively analyzed to understand further the relationship between the nanoscale topography and cell morphology (Figure 6). The elongation ratio of MSCs cultured on alumina with $100 \mathrm{~nm}$ pores was greater than that of MSCs cultured on alumina with $20 \mathrm{~nm}$ pores. Cells adhering to the $20 \mathrm{~nm}$-sized porous alumina (as well as to the smooth alumina) showed an isotropic configuration, with an overall average elongation ratio of approximately 4.9. Cells cultured on $100 \mathrm{~nm}$-sized porous alumina showed an average elongation ratio as large as about 9.5, which was significantly larger than that of the other two groups $(P<0.05)$. 
A $\quad 200.0 \mathrm{~nm}$

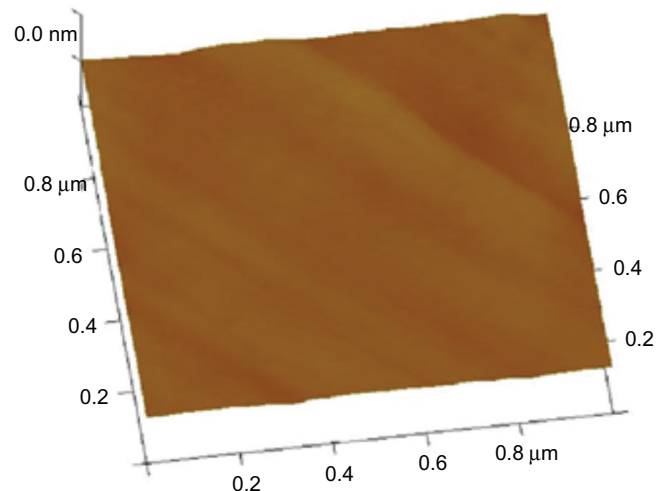

B $100.0 \mathrm{~nm}$
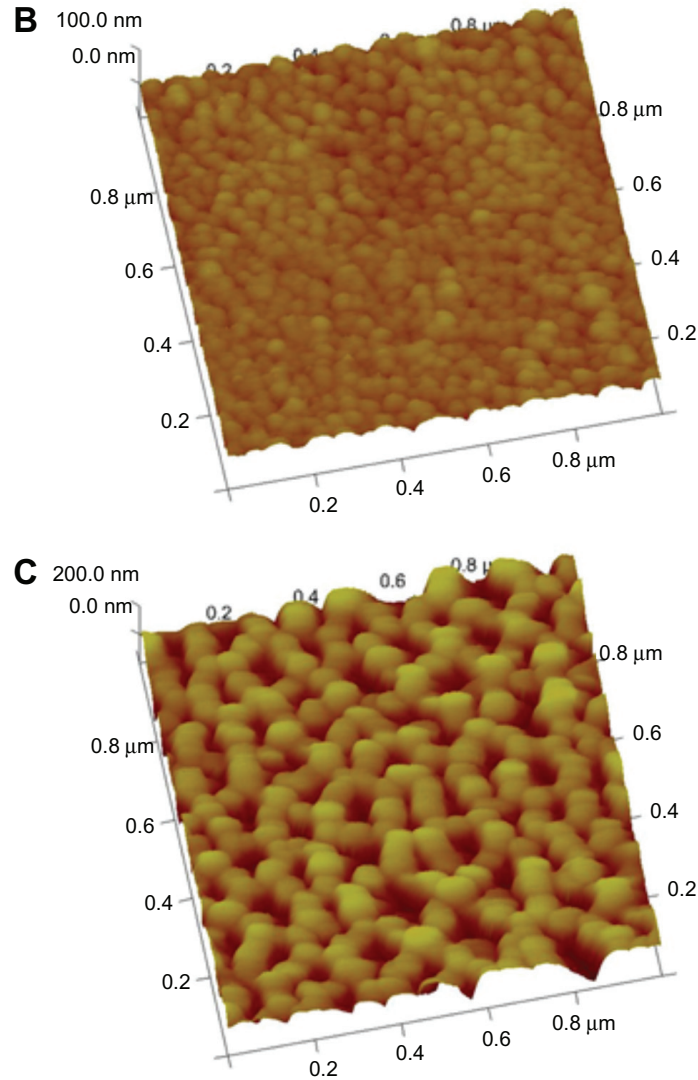

D 30

\section{0}

10

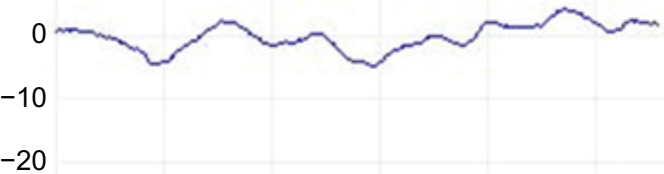

$\mathrm{nm}$ $\begin{array}{llllll}100 & 200 \quad 300 & 400 \quad 500 \quad \mathrm{~nm}\end{array}$

E

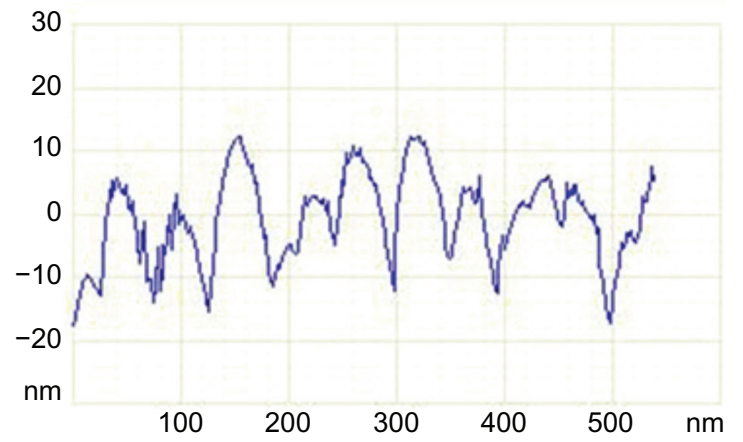

$\mathbf{F}$

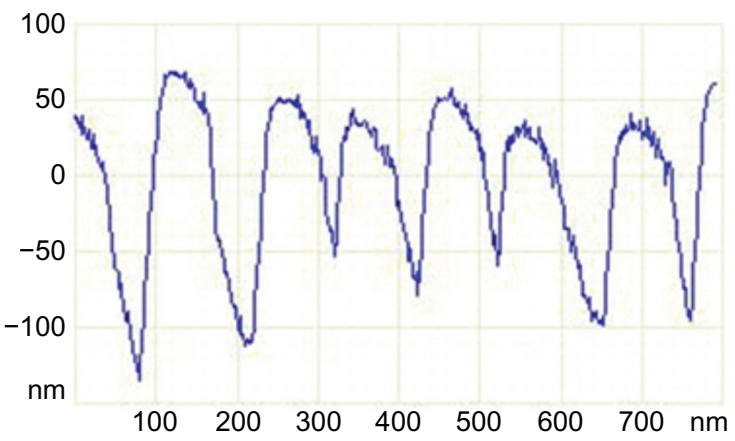

Figure 2 Atomic force microscopic images and surface relief profiles of smooth alumina (A and $\mathbf{D})$ and nanoporous alumina surfaces with pore diameters of $20 \mathrm{~nm}$ (B and $\mathbf{E})$ and $100 \mathrm{~nm}(\mathbf{C}$ and $\mathbf{F})$.

\section{Alkaline phosphatase activity}

Alkaline phosphatase activity was evaluated to investigate the osteoblastic differentiation of MSCs cultured on different substrates with the osteoblastic differentiation induction medium. Alkaline phosphatase, which is involved in the mineralization of skeletal tissues, is a membrane enzyme, the activity of which is commonly used as a marker of osteoblastic differentiation in in vitro studies. ${ }^{19}$ The alkaline phosphatase activity of MSCs was measured after incubation for 1, 2, and 3 weeks. As shown in Figure 7, significantly higher alkaline phosphatase activity was detected in MSCs cultured on nanoporous alumina substrates than those cultured on smooth alumina after 2 weeks of culture. However, the alkaline phosphatase activity of MSCs cultured on all substrates for 3 weeks was slightly lower compared with cells cultured on all substrates at week 2. The MSCs that adhered to the $100 \mathrm{~nm}$-sized porous alumina showed a relatively higher ALP activity than those adhered to the $20 \mathrm{~nm}$-sized porous alumina. 


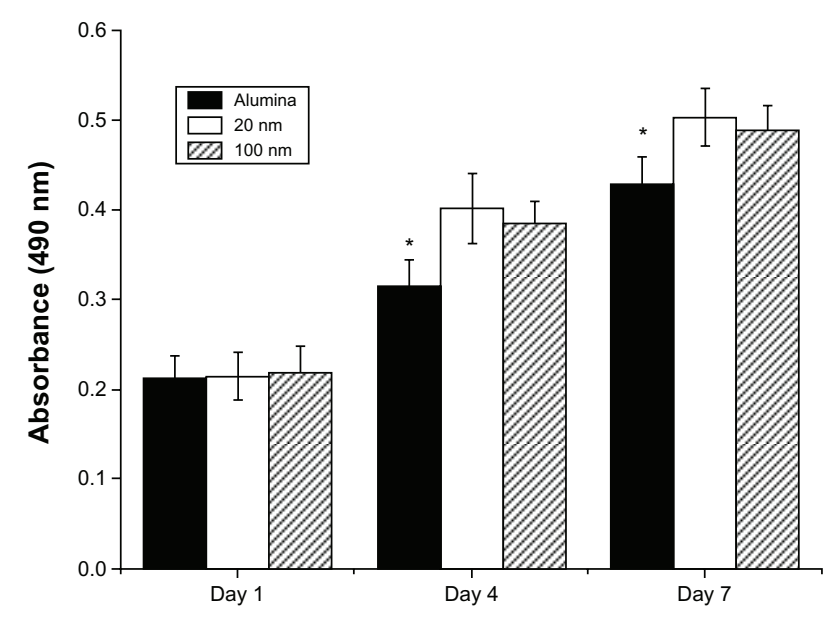

Figure 3 Effect of nanoporous alumina substrate on cell viability. Mesenchymal stem cells were cultured on nanoporous alumina or smooth alumina surfaces for I, 4, and 7 days and cell viability was measured using an MTT assay. $* P<0.05$ denotes a significant difference between the smooth alumina and nanoporous alumina.

\section{Gene expression of osteocalcin}

Osteocalcin is a bone-specific protein synthesized by osteoblasts, and represents a good marker of osteogenic maturation. ${ }^{20}$ Figure $8 \mathrm{~A}$ shows the relative osteocalcin expression of MSCs adhering to different substrates after incubation with induction medium for 3 weeks. A higher level of osteocalcin expression was detected in MSCs cultured on nanoporous alumina substrates than in those cultured on smooth alumina $(P<0.05)$. Expression of osteocalcin was enhanced in cells cultured on alumina with $100 \mathrm{~nm}$ pores compared with the $20 \mathrm{~nm}$ group.

\section{Mineralization of MSCs}

Mineralization of MSCs cultured on nanoporous alumina and smooth alumina substrates, with and without induction medium, was quantitatively measured by Alizarin red staining to detect differentiation of MSCs. Figure 8B demonstrates the quantified mineralization of MSCs on different substrates with and without induction medium after incubation for 4 weeks. MSCs cultured on alumina substrates without induction medium showed lower mineralization. Mineralization was greater in cells cultured on nanoporous alumina compared with those cultured on smooth alumina, but the difference was not significant. However, mineralization of cells cultured on nanoporous alumina with osteogenic induction medium was significantly higher than that detected in cells cultured on smooth alumina with induction medium.

\section{Discussion}

It is well known that the cellular microenvironment plays an important role in regulating cell behavior. Cellular responses to materials, such as adhesion, migration, cytoskeleton development, proliferation, and differentiation, are highly affected by material surface characteristics. ${ }^{21}$
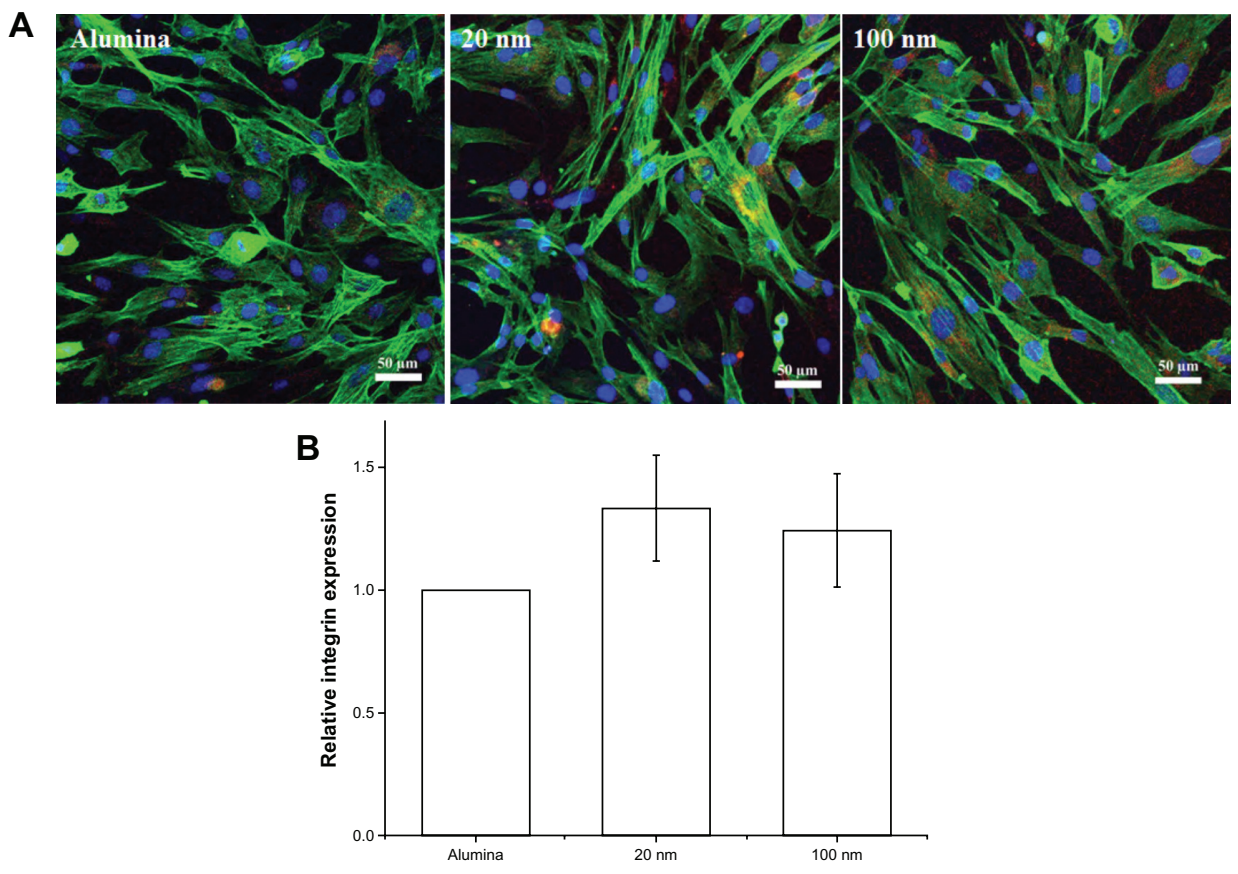

Figure 4 Immunofluorescence staining (A) and quantitative polymerase chain reaction analysis (B) of integrin $\beta$ I expression in mesenchymal stem cells adhered to different substrates after incubation for 2 days. Cells were triple-stained with actin filaments (green), cell nuclei (blue), and integrin $\beta \mid$ (red). The expression level of integrin $\beta$ I was normalized to glyceraldehyde 3-phosphate dehydrogenase and calculated using the standard curve method. 


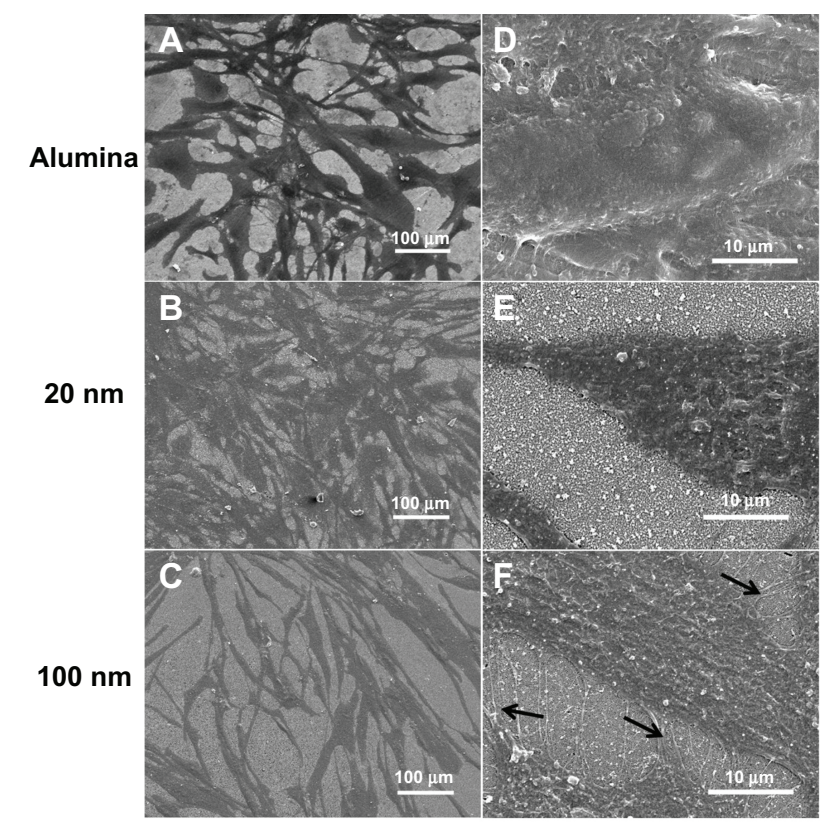

Figure 5 Scanning electron microscopic images of mesenchymal stem cells on smooth alumina or nanoporous alumina substrates with different pore sizes after incubation for 4 days: smooth alumina (A and $\mathbf{D}$ ), $20 \mathrm{~nm}$ pores (B and $\mathbf{E}$ ), and $100 \mathrm{~nm}$ pores $(\mathbf{C}$ and $\mathbf{F})$. Black arrows indicate membrane protrusions.

Compared with MSCs cultured on smooth alumina, cells grown on nanoporous alumina substrates showed higher cell viability $(P<0.05)$ after incubation for 4 and 7 days. Additionally, higher cell viability was detected in cells cultured on $20 \mathrm{~nm}$-sized nanoporous alumina substrates. This result demonstrates that the surface topography of nanoporous alumina did affect viability of cells. Popat et al demonstrated that proliferation of human fetal osteoblasts was higher in cells cultured on alumina with $90 \mathrm{~nm}$ pores than in those cultured on alumina with $200 \mathrm{~nm}$ pores. ${ }^{22}$ Chung et al demonstrated that proliferation of epithelial cells was higher

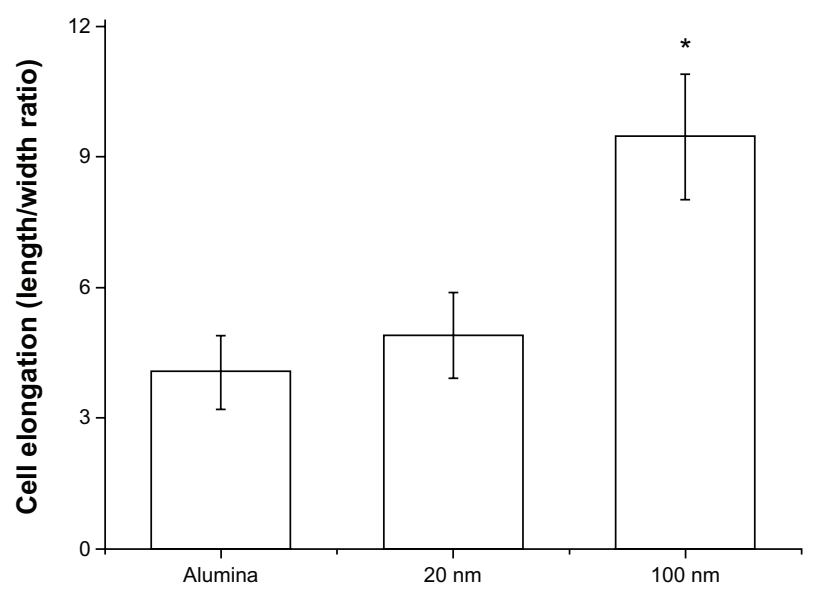

Figure 6 Effect of nanoporous alumina substrates on morphologic elongation of mesenchymal stem cells. $* P<0.05$ indicates a significant difference between the $100 \mathrm{~nm}$ pore group and the other two groups.

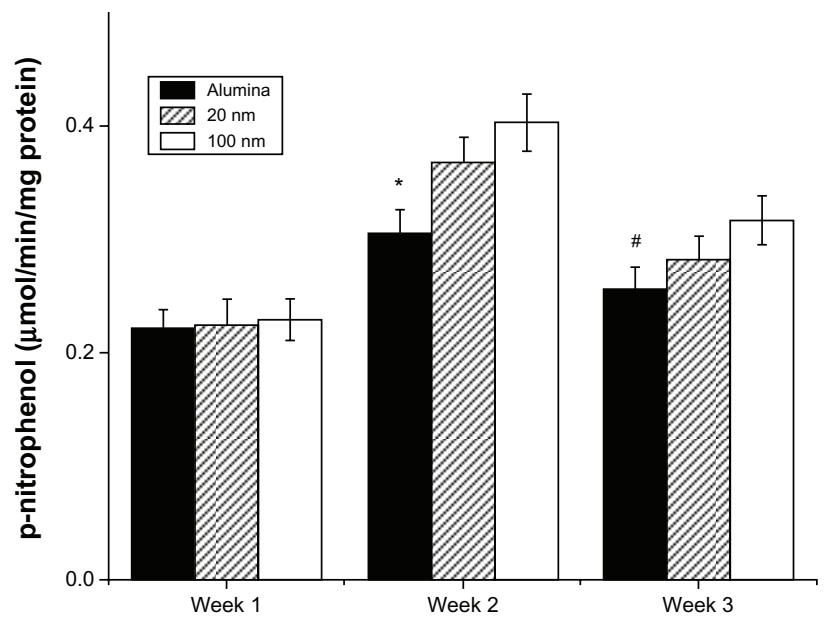

Figure 7 Effect of nanoporous alumina substrates on alkaline phosphatase activity. Mesenchymal stem cells were incubated on nanoporous alumina surfaces or smooth alumina for I, 2, and 3 weeks. Alkaline phosphatase synthesized by mesenchymal stem cells on nanoporous alumina was normalized to total intracellular protein content. The results relative to the alkaline phosphatase activity were expressed in $\mu \mathrm{mol} / \mathrm{min} / \mathrm{mg}$ protein. ${ }^{*} P<0.05$ denotes a significant difference between the smooth alumina and nanoporous alumina. ${ }^{\#} P 0.05$ denotes a significant difference between the smooth alumina and alumina with $100 \mathrm{~nm}$ pores.

when cultured on alumina with $30 \mathrm{~nm}$ pores compared with alumina with larger pores. ${ }^{23} \mathrm{~A}$ higher proliferation rate was detected in NIH/3T3 cells cultured on alumina with $75 \mathrm{~nm}$ pores than in those cultured on alumina with $300 \mathrm{~nm}$ pores. ${ }^{24}$ Although the cell types differed, higher cell viability was consistently observed in cells cultured on alumina substrate with smaller pore sizes. In other studies in which MSCs were cultured on $\mathrm{TiO}_{2}$ nanotubes with varying diameters, higher cell viability was observed in nanotubes with a smaller diameter $(15 \mathrm{~nm}) .{ }^{25,26}$ Although different structures and materials were used, the increased cell viability on smaller substrates indicates that cell behaviors are regulated by a similar mechanism.

Cell interactions with extracellular surfaces, such as the extracellular matrix and other cells, are mediated by integrins that control cellular activities, including adhesion, changes in cell shape, proliferation, migration, differentiation, and apoptosis, in a synergistic manner with hormones and growth factors. ${ }^{27,28}$ Integrins are transmembrane receptors that mediate attachment between a cell and surrounding tissues. Integrins can transmit information from extracellular ligands to cells to regulate cell responses, such as cell migration, cell survival, and growth. This type of integrin signaling is called outside-in signaling. Outside-in signaling is dependent on adaptors or scaffold proteins that link integrins to kinases, such as focal adhesion kinase, vinculin, paxillin, and Src. ${ }^{29,30}$ Another form of integrin signaling is known as inside-out signaling, which transmits intracellular signals to 

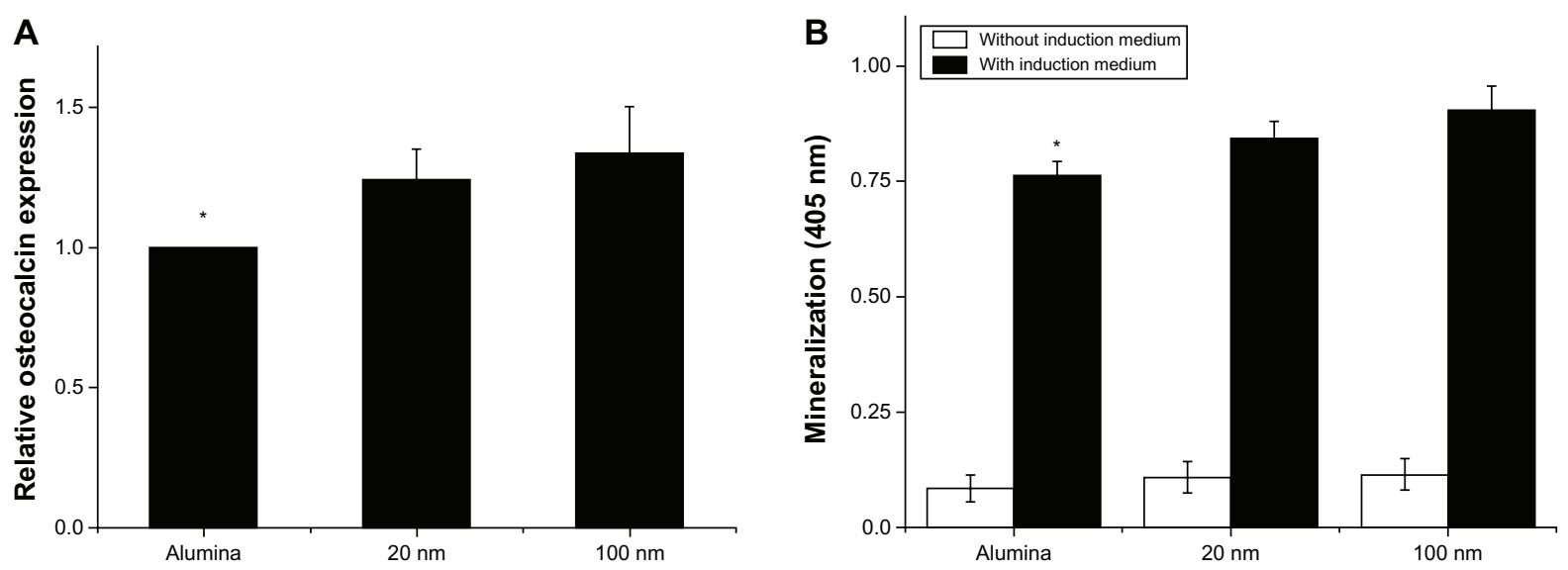

Figure 8 (A) Quantitative polymerase chain reaction analysis for osteocalcin expression. Mesenchymal stem cells were cultured on nanoporous alumina surfaces or smooth alumina for 3 weeks. Expression of GAPDH was used as an endogenous control. Expression level of osteocalcin was normalized to GAPDH and calculated using the standard curve method. (B) Mineralization of mesenchymal stem cells on different substrates after 4 weeks of incubation. $* P<0.05$ denotes a significant difference between the smooth alumina and nanoporous alumina.

Abbreviation: GAPDH, glyceraldehyde 3-phosphate dehydrogenase.

the outside of cells to regulate their affinity for extracellular ligands by undergoing conformational changes that activate the integrins..$^{31}$ Previous studies have shown that integrin $\beta 1$ is required for cell spreading, adhesion, and proliferation. ${ }^{32-34}$ The present study demonstrated that the expression level of integrin $\beta 1$ was consistent with the relationship between cell viability and alumina nanoporosity. The diameter of integrin located in the cell membrane is $8-12 \mathrm{~nm},{ }^{35,36}$ which is near the $20 \mathrm{~nm}$ size of the smaller pores in the alumina membrane. The enhanced $\beta 1$ integrin expression in MSCs cultured on alumina substrate with $20 \mathrm{~nm}$ pores indicates that a pore size of $20 \mathrm{~nm}$ is optimal for the activation of integrin through inside-out signaling, which causes conformational changes and clustering of integrin. The activated integrins can transmit the outside-in signaling into the cell nucleus by phosphorylating focal adhesion kinase and Src to regulate MSC responses, such as proliferation and differentiation. . $^{34,37-39}$

MSCs interact with the nanotopography of the porous alumina substrate by changing both their external and internal shapes. A unique pattern of cell morphology that included elongated cells and prominent filopodia was observed on alumina substrates with $100 \mathrm{~nm}$ pores. Oh et al have reported that adhesion of cells is determined by initial adsorption of fibronectin and albumin from the culture medium, and that more protein, including fibronectin and albumin, could be deposited on a surface with smaller pores. ${ }^{26}$ Dolatshahi-Pirouz et al demonstrated the importance of fibronectin-coated gold and hydroxyapatite surfaces for shape and spreading of MSCs. ${ }^{40}$ Garcia et al demonstrated that conformation of the adsorbed protein (fibronectin) was influenced by surface topography, because its specific RGD binding sequence can be either freely available or hidden. ${ }^{41}$ Fewer MSCs were attached to the alumina substrate with $100 \mathrm{~nm}$ pores due to less deposited protein, a hidden RGD binding sequence, and a larger pore-to-pore distance on a surface with larger pores. The larger pore-to-pore distance on an alumina surface with $100 \mathrm{~nm}$ pores also caused tension in the actin cytoskeleton and stress on the MSCs, and ultimately caused elongated cell morphology.

Cell morphology is regarded as a determinant of cell growth, cytoskeletal arrangement, and differentiation for a variety of cell types. ${ }^{42-44} \mathrm{McBeath}$ et al found that cell shape plays an important role in osteogenic differentiation of MSCs by regulating local focal adhesion assembly and the actin cytoskeleton. ${ }^{45}$ Additionally, integrin subunits are known to be critical for activating focal adhesion kinase. ${ }^{38}$ The changes in cell morphology observed in the present study therefore affected the growth behavior and osteogenic differentiation of MSCs.

Surface contact area also plays an important role in cell adhesion and proliferation. Alumina surfaces with $20 \mathrm{~nm}$ pores had a larger contact area than the surfaces with $100 \mathrm{~nm}$ pores. When MSCs were first seeded on the substrates, it was easier for them to adhere to the substrates with $20 \mathrm{~nm}$ pores because of the larger contact area, which led to greater proliferation and more cell spreading. In contrast, MSCs cultured on alumina substrates with $100 \mathrm{~nm}$ pores had to elongate to obtain sufficient contact area for adherence. This explains the greater cell elongation observed in the $100 \mathrm{~nm}$ group.

Differentiation of stem cells is affected by many factors. Pittenger et $\mathrm{a}^{46}$ and McBeath et a ${ }^{45}$ reported that the initial cell-seeding density plays a critical role in the differentiation 
of MSCs. MSCs seeded at a lower cell density displayed better osteoblastic differentiation in the presence of a medium inducing osteogenesis. We have demonstrated in the present study that an alumina surface with $100 \mathrm{~nm}$ pores produces a lower cell number than that with $20 \mathrm{~nm}$ pores; however, an alumina surface with larger pores produces more osteogenic differentiation markers. It seems that the initial cell density has a lasting effect on the eventual fate of stem cells. Growth factors have been intensively studied as traditional regulatory factors in stem cell research. MSCs can be induced to differentiate into osteoblasts in vitro in the presence of dexamethasone, ascorbic acid, and $\beta$-glycerol phosphate. ${ }^{47}$ Bone morphogenetic proteins are members of the transforming growth factor- $\beta$ superfamily, and play a central role in bone formation by inducing differentiation of MSCs into osteoblasts. ${ }^{48}$ Insulin-like growth factor I has been demonstrated to induce early osteoblastic differentiation of human MSCs. ${ }^{49}$ Nanotopography is now receiving more interest due to its advantageous features such as a larger surface-to-volume ratio and a higher degree of biological plasticity than conventional microstructures or macrostructures. ${ }^{26}$ Previous studies have shown that adhesion, migration, and proliferation of MSCs as well as their differentiation into osteoblasts are all strongly dependent on surface topography at the nanoscale. ${ }^{50,51}$ Dalby et al reported that randomly placed nanotopographies were able to induce osteogenic differentiation of MSCs. ${ }^{52}$

Osteoblastic differentiation markers, including alkaline phosphatase activity, osteocalcin expression, and mineralization, were measured in the present study to validate the effect of nanoporous alumina on osteogenic differentiation of MSCs in induction medium. The enzymatic activity of alkaline phosphatase was quantitatively calculated to evaluate early osteogenic activity. MSCs cultured on alumina with $100 \mathrm{~nm}$ pores showed higher alkaline phosphatase activity than the $20 \mathrm{~nm}$ and smooth alumina groups. Alkaline phosphatase activity of MSCs was relatively lower after 3 weeks of culture than after 2 weeks of culture. Alkaline phosphatase activity is an established marker that is expressed in the early stage of osteoblastic differentiation. The decreased alkaline phosphatase activity seen in this study might be due to the fact that the differentiation of MSCs had already passed the early stage and reached the middle/late stage. ${ }^{53}$

Osteoblastic differentiation of MSCs into functional differentiated osteoblasts requires a series of steps involving a number of proteins being expressed at each stage. Alkaline phosphatase is regarded as a marker for early osteoblastic differentiation, whereas secretion of osteocalcin and matrix mineralization are associated with the final differentiation phase. The expression of osteocalcin was therefore measured. By analyzing the PCR data, higher levels of osteocalcin were detected in MSCs cultured on alumina with $100 \mathrm{~nm}$ pores than in those cultured on $20 \mathrm{~nm}$-sized pores and smooth alumina substrates.

Mineralization was measured after incubation for 4 weeks to evaluate osteogenic differentiation of MSCs on nanoporous alumina surfaces with and without induction medium. We found that MSCs cultured on alumina substrates without induction medium showed lower mineralization. Cells cultured on nanoporous alumina showed greater mineralization than cells cultured on smooth alumina, and the greatest mineralization occurred in cells cultured on alumina with $100 \mathrm{~nm}$ pores, but neither of these differences were found to be statistically significant. Significantly higher mineralization was detected in cells cultured on nanoporous alumina than in those cultured on smooth alumina. These results demonstrate that nanoporous alumina can induce differentiation of MSCs, and can significantly promote the differentiation effect of MSCs in the presence of osteogenic induction medium. Many studies have reported that substrate topography, such as that of nanotubes, ${ }^{26}$ nanopillars, ${ }^{52}$ and other nanostructures, ${ }^{54,55}$ can induce osteogenic differentiation of MSCs, although other research has indicated that three-dimensional polycaprolactone scaffolds cannot induce osteogenic differentiation of MSCs. ${ }^{56}$ These results indicate that substrate nanotopography combined with the presence of induction medium were advantageous for inducing differentiation of MSCs.

Osteoblast differentiation occurs through a multistep molecular pathway regulated by different transcription factors and signaling proteins, including Runx2, Osterix, and Wnt. The most important of those transcription factors for osteogenic differentiation is Runx2. Runx2 is a key transcriptional modulator of osteoblast differentiation that plays a fundamental role in osteoblast maturation and homeostasis by interacting with numerous transcription factors and coactivators to integrate signaling events within the cell nucleus. ${ }^{57,58}$ The molecular mechanisms by which Runx2 controls bone formation have been identified. By binding to the osteoblast-specific cis-acting sequence PuACCPuCA, ${ }^{59-61}$ the Runx regulatory element regulates expression of several osteoblast genes, including alkaline phosphatase, type I collagen, osteopontin, bone sialoprotein, and osteocalcin, resulting in the establishment of an osteoblast phenotype. ${ }^{62,63}$ Recent work has demonstrated that the integrin-linked kinase/ $\beta$-catenin pathway is also 
important in mediating signals from topographic cues to direct osteogenic differentiation of cells. ${ }^{64}$

In this study, nanoporous alumina substrates with pore sizes of $20 \mathrm{~nm}$ and $100 \mathrm{~nm}$ were selected to evaluate the proliferation and differentiation of MSCs. Alumina with $100 \mathrm{~nm}$ pores showed the highest osteogenic differentiation capacity among the substrates tested. The effect of alumina with other pore sizes (eg, larger than $100 \mathrm{~nm}$ or between $20 \mathrm{~nm}$ and $100 \mathrm{~nm}$ ) on the differentiation of MSCs is still unclear. Further studies are needed to determine the sensitivity of MSCs to alumina pore size.

\section{Conclusion}

The present study investigated the effect of alumina nanotopography on the behavior of MSCs, as measured by cell proliferation, morphology, and osteogenic differentiation. We found that cell adhesion, proliferation, and differentiation are strongly correlated with alumina pore size. Reduced cell numbers, increased cell elongation, and prominent filopodia were documented in cells cultured on the alumina surfaces with larger pore sizes. MSCs cultured on nanoporous alumina with $100 \mathrm{~nm}$ pores also showed higher osteoblast differentiation in the presence of induction medium. The beneficial effects of the surface topography of nanoporous alumina on cell behavior suggest that this novel biocompatible material, when used in combination with stem cells, can serve as an effective tissue-engineering scaffold in therapeutic and regenerative medicine.

\section{Acknowledgment}

This work was supported by the Japan Society for the Promotion of Science under a Grant-in-Aid for Scientific Research (A23246024).

\section{Disclosure}

The authors report no conflicts of interest in this work.

\section{References}

1. Ratner BD, Bryant SJ. Biomaterials: where we have been and where we are going. Annu Rev Biomed Eng. 2004;6:41-75.

2. Wennerberg A, Albrektsson T, Andersson B. An animal study of c.p. titanium screws with different surface topographies. JMater Sci Mater M. 1995;6:302-309.

3. Li LH, Kong YM, Kim HW, et al. Improved biological performance of Ti implants due to surface modification by micro-arc oxidation. Biomaterials. 2004;25:2867-2875.

4. Lord MS, Foss M, Besenbacher F. Influence of nanoscale surface topography on protein adsorption and cellular response. Nano Today. 2010;5:66-78.

5. Wan Y, Wang Y, Liu Z, et al. Adhesion and proliferation of OCT-1 osteoblast-like cells on micro- and nano-scale topography structured poly(L-lactide). Biomaterials. 2005;26:4453-4459.
6. Théry M, Racine V, Pépin A, et al. The extracellular matrix guides the orientation of the cell division axis. Nat Cell Biol. 2005;7:947-953.

7. Wang L, Lei L, Ni XF, Chen Y. Patterning bio-molecules for cell attachment at single cell levels in PDMS microfluidic chips. Microelectron Eng. 2009;86:1462-1464.

8. Tamai N, Myoui A, Tomita T, et al. Novel hydroxyapatite ceramics with an interconnective porous structure exhibit superior osteoconduction in vivo. J Biomed Mater Res. 2002;59:110-117.

9. Hing KA. Bioceramic bone graft substitutes: influence of porosity and chemistry. Int J Appl Ceram Technol. 2005;2:184-199.

10. Karlsson M, Pålsgård E, Wilshaw PR, Di Silvio L. Initial in vitro interaction of osteoblasts with nanoporous alumina. Biomaterials. 2003;24: 3039-3046.

11. Swan EL, Popat KC, Desai TA. Peptide immobilized nanoporous alumina membranes for enhanced osteoblast adhesion. Biomaterials. 2005;26:1969-1976.

12. Hoess A, Teuscher N, Thormann A, Aurich H, Heilmann A. Cultivation of hepatoma cell line HepG2 on nanoporous aluminum oxide membranes. Acta Biomater. 2007;3:43-50.

13. Marinucci L, Balloni S, Becchetti E, et al. Effects of hydroxyapatite and biostite on osteogenic induction of hMSC. Ann Biomed Eng. 2010;38: 640-648.

14. Zannettino A, Paton S, Arthur A, et al. Multipotential human adiposederived stromal stem cells exhibit a perivascular phenotype in vitro and in vivo. J Cell Physiol. 2008;214:413-421.

15. Engler AJ, Sen S, Sweeney HL, Discher DE. Matrix elasticity directs stem cell lineage specification. Cell. 2006;126:677-689.

16. Morganstein DL, Wu P, Mane MR, Fisk NM, White R, Parker MG. Human fetal mesenchymal stem cells differentiate into brown and white adipocytes: a role for ERR $\alpha$ in human UCP1 expression. Cell Res. 2010;20:434-444.

17. Xu B, Song G, Ju Y. Effect of focal adhesion kinase signaling on the regulation of alignment and tenogenic differentiation of human mesenchymal stem cells by mechanical stretch. Connect Tissue Res. 2011;52: 373-379.

18. Park J, Bauer S, Schlegel KA, Neukam FW, von der Mark K, Schmuki P.TiO nanotube surfaces: $15 \mathrm{~nm}$-an optimal length scale of surface topography for cell adhesion and differentiation. Small. 2009;5:666-671.

19. Gotoh Y, Hiraiwa K, Nagayama M. In vitro mineralization of osteoblastic cells derived from human bone. Bone Miner. 1990;8:239-250.

20. Nakamura A, Dohi Y, Akahane M, et al. Osteocalcin secretion as an early marker of in vitro osteogenic differentiation of rat mesenchymal stem cells. Tissue Eng Part C Methods. 2009;15:169-180.

21. Dalby MJ, Di Silvio L, Harper EJ, Bonfield W. In vitro adhesion and biocompatibility of osteoblast-like cells to poly(methylmethacrylate) and poly(ethylmethacrylate) bone cements. J Mater Sci Mater Med. 2002;13:311-314.

22. Popat KC, Leary Swan EE, Mukhatyar V, et al. Influence of nanoporous alumina membranes on long-term osteoblast response. Biomaterials. 2005;26:4516-4522.

23. Chung SH, Son SJ, Min J. The nanostructure effect on the adhesion and growth rates of epithelial cells with well-defined nanoporous alumina substrate. Nanotechnology. 2010;21:125104-125110.

24. Hu J, Tian JH, Shi J, et al. Cell culture on AAO nanoporous substrates with and without geometry constraints. Microelectron Eng. 2011;88: 1714-1717.

25. Park J, Bauer S, von der Mark K, Schmuki P. Nanosize and vitality: TiO2 nanotube diameter directs cell fate. Nano Lett. 2007;7:1686-1691.

26. Oh S, Brammer KS, Li YS, et al. Stem cell fate dictated solely by altered nanotube dimension. Proc Natl Acad Sci U S A. 2009;106: 2130-2135.

27. Burridge K, Chrzanowska-Wodnicka M. Focal adhesions, contractility, and signaling. Annu Rev Cell Dev Biol. 1996;12:463-518.

28. Giancotti FG. A structural view of integrin activation and signaling. Dev Cell. 2003;4:149-151.

29. Schlaepfer DD, Hauck CR, Sieg DJ. Signaling through focal adhesion kinase. Prog Biophys Mol Biol. 1999;71:435-478. 
30. Mitra SK, Hanson DA, Schlaepfer DD. Focal adhesion kinase: in command and control of cell motility. Nat Rev Mol Cell Biol. 2005;6: 56-68.

31. Calderwood DA. Integrin activation. J Cell Sci. 2004;117:657-666.

32. Rowland TJ, Miller LM, Blaschke AJ, et al. Roles of integrins in human induced pluripotent stem cell growth on Matrigel and vitronectin. Stem Cells Dev. 2010;19:1231-1240.

33. Abraham S, Kogata N, Fässler R, Adams RH. Integrin beta1 subunit controls mural cell adhesion, spreading, and blood vessel wall stability. Circ Res. 2008;102:562-570.

34. Cavalcanti-Adam EA, Volberg T, Micoulet A, Kessler H, Geiger B, Spatz JP. Cell spreading and focal adhesion dynamics are regulated by spacing of integrin ligands. Biophys J. 2007;92:2964-2974.

35. Xiong JP, Stehle T, Diefenbach B, et al. Crystal structure of the extracellular segment of integrin alpha Vbeta3. Science. 2001;294:339-345.

36. Erb EM, Tangemann K, Bohrmann B, Müller B, Engel J. Integrin alphaIIb beta3 reconstituted into lipid bilayers is nonclustered in its activated state but clusters after fibrinogen binding. Biochemistry. 1997;36:7395-7402.

37. DeMali KA, Wennerberg K, Burridge $\mathrm{K}$. Integrin signaling to the actin cytoskeleton. Curr Opin Cell Biol. 2003;15:572-582.

38. Shibue T, Weinberg RA. Integrin beta1-focal adhesion kinase signaling directs the proliferation of metastatic cancer cells disseminated in the lungs. Proc Natl Acad Sci U S A. 2009;106:10290-10295.

39. Arnold M, Cavalcanti-Adam EA, Glass R, et al. Activation of integrin function by nanopatterned adhesive interfaces. Chemphyschem. 2004;5: 383-388.

40. Dolatshahi-Pirouz A, Jensen TH, Kolind K, et al. Cell shape and spreading of stromal (mesenchymal) stem cells cultured on fibronectin coated gold and hydroxyapatite surfaces. Colloids Surf B Biointerfaces. 2011;84:18-25.

41. García AJ, Vega MD, Boettiger D. Modulation of cell proliferation and differentiation through substrate-dependent changes in fibronectin conformation. Mol Biol Cell. 1999;10:785-798.

42. Gao L, McBeath R, Chen CS. Stem cell shape regulates a chondrogenic versus myogenic fate through Rac1 and N-cadherin. Stem Cells. 2010;28:564-572.

43. Folkman J, Moscona A. Role of cell shape in growth control. Nature. 1978;273:345-349.

44. Haeuptle MT, Suard YL, Bogenmann E, Reggio H, Racine L, Kraehenbuhl JP. Effect of cell shape change on the function and differentiation of rabbit mammary cells in culture. J Cell Biol. 1983;96: 1425-1434.

45. McBeath R, Pirone DM, Nelson CM, Bhadriraju K, Chen CS. Cell shape, cytoskeletal tension, and RhoA regulate stem cell lineage commitment. Dev Cell. 2004;6:483-495.

46. Pittenger MF, Mackay AM, Beck SC, et al. Multilineage potential of adult human mesenchymal stem cells. Science. 1999;284:143-147.

47. Jaiswal N, Haynesworth SE, Caplan AI, Bruder SP. Osteogenic differentiation of purified, culture expanded human mesenchymal stem cells in vitro. J Cell Biochem. 1997;64:295-312.

48. Lieberman JR, Daluiski A, Einhorn TA. The role of growth factors in the repair of bone. Biology and clinical applications. J Bone Joint Surg Am. 2002;84:1032-1044.
49. Koch H, Jadlowiec JA, Campbell PG. Insulin-like growth factor-I induces early osteoblast gene expression in human mesenchymal stem cells. Stem Cells Dev. 2005;14:621-631.

50. Lavenus S, Berreur M, Trichet V, Pilet P, Louarn G, Layrolle P. Adhesion and osteogenic differentiation of human mesenchymal stem cells on titanium nanopores. Eur Cell Mater. 2011;22:84-96.

51. Zouani OF, Chanseau C, Brouillaud B, et al. Altered nanofeature size dictates stem cell differentiation. J Cell Sci. 2012;125:1217-1224.

52. Dalby MJ, Gadegaard N, Tare R, et al. The control of human mesenchymal cell differentiation using nanoscale symmetry and disorder. Nat Mater. 2007;6:997-1003.

53. Owen TA, Aronow M, Shalhoub V, et al. Progressive development of the rat osteoblast phenotype in vitro: reciprocal relationships in expression of genes associated with osteoblast proliferation and differentiation during formation of the bone extracellular matrix. $J$ Cell Physiol. 1990;143:420-430.

54. Sjöström T, Dalby MJ, Hart A, et al. Fabrication of pillar-like titania nanostructures on titanium and their interactions with human skeletal stem cells. Acta Biomater. 2009;5:1433-1441.

55. George J, Kuboki Y, Miyata T. Differentiation of mesenchymal stem cells into osteoblasts on honeycomb collagen scaffolds. Biotechnol Bioeng. 2006;95:404-411.

56. Zhang H, Migneco F, Lin CY, et al. Chemically-conjugated bone morphogenetic protein-2 on three-dimensional polycaprolactone scaffolds stimulates osteogenic activity in bone marrow stromal cells. Tissue Eng Part A. 2010;16:3441-3448.

57. Pungchanchaikul P, Bloch-Zupan A, Ferretti P. Delayed osteoprogenitor differentiation in cleft-palate models. Cells Tissues Organs. 2010;192: 283-291.

58. Lee JS, Lee JM, Im GI. Electroporation-mediated transfer of Runx2 and Osterix genes to enhance osteogenesis of adipose stem cells. Biomaterials. 2011;32:760-768.

59. de Crombrugghe B, Lefebvre V, Nakashima K. Regulatory mechanisms in the pathways of cartilage and bone formation. Curr Opin Cell Biol. 2001;13:721-727.

60. Yoshida CA, Furuichi T, Fujita T, et al. Core-binding factor beta interacts with Runx 2 and is required for skeletal development. Nat Genet. 2002;32:633-638.

61. Ducy P, Karsenty G. Two distinct osteoblast-specific cisacting elements control expression of a mouse osteocalcin gene. Mol Cell Biol. $1995 ; 15: 1858-1869$.

62. Zhang S, Xiao Z, Luo J, He N, Mahlios J, Quarles LD. Dosedependent effects of Runx 2 on bone development. J Bone Miner Res. 2009;24:1889-1904.

63. Jang WG, Kim EJ, Kim DK, et al. BMP2 protein regulates osteocalcin expression via Runx2-mediated Atf6 gene transcription. J Biol Chem. 2012;287:905-915.

64. Wang W, Zhao L, Wu K, et al. The role of integrin-linked kinase/ $\beta$ catenin pathway in the enhanced MG63 differentiation by micro/ nano-textured topography. Biomaterials. 2013;34:631-640.
International Journal of Nanomedicine

\section{Publish your work in this journal}

The International Journal of Nanomedicine is an international, peerreviewed journal focusing on the application of nanotechnology in diagnostics, therapeutics, and drug delivery systems throughout the biomedical field. This journal is indexed on PubMed Central, MedLine, CAS, SciSearch $\AA$, Current Contents ${ }^{\circledR} /$ Clinical Medicine,
Dovepress

Journal Citation Reports/Science Edition, EMBase, Scopus and the Elsevier Bibliographic databases. The manuscript management system is completely online and includes a very quick and fair peer-review system, which is all easy to use. Visit http://www.dovepress.com/ testimonials.php to read real quotes from published authors. 